\title{
El transporte terrestre a través del espacio rioplatense durante las primeras décadas del período independiente
}

\author{
Miguel Ángel Rosal \\ CONICET-Instituto Ravignani, \\ Buenos Aires, Argentina
}

\begin{abstract}
Gran parte del espacio rioplatense, sin ríos navegables, ni acceso al mar, dependió de tropas de carretas tiradas por bueyes y recuas de mulas para la satisfacción de su demanda de transporte hasta bien entrada la segunda mitad del siglo XIX, cuando comenzó a extenderse la red ferroviaria. Si bien el sistema de transporte terrestre implementado tenía a su favor ciertas diferencias regionales en los recursos y una considerable cantidad de asentamientos, estos beneficios no siempre lograron compensar las dificultades que significaban el estado de los caminos (simples huellas abiertas a través de las pampas, que poca o ninguna atención recibían por parte de las autoridades, y que en ocasiones eran mejoradas por los propios transportistas) y las largas distancias entre los dispersos poblados. Además, tal sistema no era totalmente especializado y tuvo variados impedimentos que interferían su cometido.

En síntesis, el funcionamiento del transporte terrestre rioplatense se enfrentó, hasta la llegada del ferrocarril, a distintos inconvenientes, que si bien entorpecieron el logro de una adecuada integración, no impidieron una relativa fluidez en la circulación de personas y recursos entre las diversas y distantes áreas del territorio en cuestión.
\end{abstract}

El presente estudio es una suerte de continuación de otros que sobre el mismo tema y referidos al lapso colonial hemos realizado hace ya algunos años y, a la vez, complementa la investigación que llevamos a cabo sobre el comportamiento y dirección de los flujos comerciales durante la época rosista, ${ }^{1}$ donde pudimos apreciar la intensidad de las conexiones comerciales que fueron entretejiendo las distintas regiones-provincias rioplatenses y su capital en esa lenta agregación de mercados regionales que

1 Ver Rosal, Miguel A.: "Transportes terrestres y circulación de mercancías en el espacio rioplatense, 1781-1811", en Anuario del IEHS, n. ${ }^{\circ}$ 3, Tandil, 1989, págs. 123-159; "El transporte hacia Buenos Aires a través de la hidrovía Paraguay-Paraná, 1781-1811”. en Jahrbuch für Geschichte von Staat, Wirtschaft und Gesellschaft Lateinamerikas, Band 27, Köln, 1990, págs. 127-147; "Los transportes durante la primera década post-revolucionaria; la quiebra de un sistema", en $L a$ Gaceta Americana, n. ${ }^{\circ}$ 7, Buenos Aires, nov.-dic. de 1990, págs. 15-25; y "El Interior frente a Buenos Aires: flujos comerciales e integración económica, 1831-1850”, en Secuencia, n. ${ }^{\circ}$ 31, México, 1995, págs. 51-111. 
subyace en toda formación de un mercado nacional; obviamente, estamos hablando de un territorio que aún no constituía una nación propiamente dicha.

La desarticulación del mercado rioplatense-altoperuano a partir de 1810 produjo en el primero de los espacios mencionados el comienzo de un proceso sin retorno que culminó en una vinculación plena con el Atlántico. Obviamente, la historia terminó así, pero creemos que no necesariamente tuvo que ser de ese modo; en todo caso, hay varias razones para pensar que durante la primera mitad del siglo XIX pudo haber más mutilaciones que las sufridas a partir de la Revolución en el espacio presuntamente dominado por Buenos Aires.

No todas las regiones-provincias, ya fuera por la calidad y cantidad de sus recursos naturales, y/o por razones geográficas, pudieron adaptarse rápidamente a la dislocación del antiguo orden. De allí que la conexión comercial de aquéllas con Buenos Aires tuvo distintos niveles de intensidad, pasando desde el tendido de unas débiles ligaduras, casi inexistentes, hasta el entrelazamiento de firmes nexos con el puerto, siempre en función de un ávido mercado exterior de ciertas materias primas, en especial las derivadas de la ganadería.

En ese sentido, mientras el Litoral logró, siempre a través de Buenos Aires, fuertes lazos con los mercados ultramarinos, las provincias norteñas de lo que más tarde sería la Argentina, por su parte, conformaron la periferia de un nuevo espacio mercantil, cuyo núcleo se asentaba en el antiguo Alto Perú (aun con ocasionales envíos, ya fueran directos a Buenos Aires o que se dirigieran a Córdoba, la cual los reexportaba hacia el puerto). Las cuyanas, en tanto, no obstante sus conexiones con dicho mercado, parecían más predispuestas a recostarse sobre el Pacífico, exceptuando los períodos de bloqueos, cuando la desabastecida Buenos Aires necesitaba imperiosamente los caldos cuyanos, si bien la producción de los mismos estaba en franca decadencia.

Buenos Aires, en tanto, disfrutaba de un período de expansión económica basada en la ganadería, cuyos productos eran, como hemos dicho, altamente apreciados como materia prima por la industrialización europea. Mantenía, además, el control sobre los derechos aduaneros y, al prohibir la libre navegación de los ríos interiores, se reservaba los servicios de intermediación.

Así presentado el problema ¿fue inevitable que la balanza se inclinara hacia el puerto? Aun cuando no tenemos cifras globales concretas res- 
pecto a los flujos mercantiles hacia las salidas alternativas al mercado porteño, la articulación plena del espacio rioplatense con el Atlántico parecía ser sólo cuestión de tiempo; sin embargo, el peligro de desintegración económica del mismo estuvo siempre latente.

Fue en este contexto donde operó un sistema de transporte terrestre con variadas limitaciones que no contribuyeron, precisamente, a lograr la integración territorial. ${ }^{2}$ Gran parte del espacio rioplatense, sin ríos navegables, ni acceso al mar, dependió de tropas de carretas tiradas por bueyes y recuas de mulas para la satisfacción de su demanda de transporte hasta bien entrada la segunda mitad del siglo XIX, cuando comenzó a extenderse la red ferroviaria. Si bien el sistema de transporte terrestre implementado tenía a su favor ciertas diferencias regionales en los recursos y una considerable cantidad de asentamientos, estos beneficios no siempre lograron compensar las dificultades que significaban el estado de los caminos (simples huellas abiertas a través de las pampas, que poca o ninguna atención recibían por parte de las autoridades, ${ }^{3}$ y que en ocasiones eran mejoradas por los propios transportistas) y las largas distancias entre los dispersos poblados.

Hasta la llegada del ferrocarril, pues, estos obstáculos limitaron dicho sistema a tropas y arrias, que, como veremos, no era totalmente especializado, con variados impedimentos que interferían su cometido y, no siempre eficaz, para vencer distancias y desafíos climáticos y topográficos, o para movilizar considerables volúmenes de bienes hasta los mercados consumidores.

En todo caso, debemos tener en cuenta que los dos medios de comunicación más avanzados en Europa para esos tiempos, los canales y las carreteras "empedradas", obras que exigían un cuantioso capital para ser llevadas a cabo, habían fracasado en la propia España, ${ }^{4}$ por lo que muy difícilmente pudieran plasmarse en el Río de la Plata. Es así como el sistema de transporte implementado durante la época hispánica, a grandes rasgos siguió funcionando casi sin variantes hasta la segunda mitad del siglo XIX. Las vicisitudes que sufrió tal sistema quedan fielmente reflejadas en los

2 La implementación del transporte fluvial a través de vías de comunicación naturales tales como los ríos Paraná y Uruguay permitió una performance algo más eficiente para la zona del Litoral.

3 Las mejoras de la red vial eran impensables dada la falta de una autoridad central y el estado casi permanente de guerra civil entre los distintos estados provinciales. Brown, Jonathan: $A$ Socioeconomic History Of Argentina, 1776-1860, Cambridge University Press, 1979, págs. 209-210.

4 Sobre el tema se puede consultar a Ringrose, David R.: Los transportes y el estancamiento económico de España (1750-1850), Madrid, 1972. 
conceptos que sobre el tema realizó Braudel al compararlas con las que se experimentaron en parte del Viejo Mundo algunos siglos antes:

"La ruda Argentina de las primeras décadas de la independencia evoca mil realidades del siglo XVI mediterráneo, con sus enormes retrasos a lo largo de los caminos, a través del Atlántico o sobre tierra americana; las falsas noticias o las noticias demasiado viejas hacían afluir a Buenos Aires las pesadas carretas desde el fondo de la pampa (y el trigo que creían transportar en sazón oportuna para comerciar con él llegaba muchas veces a un puerto que, entretanto, se había saturado y donde ya no tenía salida". ${ }^{5}$

\section{Distancias y rutas comerciales}

El itinerario Real de Postas, que data de la primera década del siglo XIX, establecía las distancias entre los distintos centros urbanos del territorio rioplatense midiéndolas en leguas. Convendría, en todo caso, precisar qué longitud tiene una legua. En España, es una medida itineraria equivalente a $5572 \mathrm{~m} 7 \mathrm{dm}$; sin embargo, la legua "de posta" mide unos $4 \mathrm{~km}$ $(4189 \mathrm{~m})$. La gran variedad de fuentes utilizadas para realizar este trabajo no determina la longitud de la legua, pero probablemente se están refiriendo a las leguas de posta. En todo caso, no pensamos que se pueda hablar de distancias firmemente establecidas, dado que los transportistas en muchas ocasiones "hacían camino al andar", no sólo por el ejercicio de una idea firmemente arraigada de libertad de tránsito, sino también por el imperio de las circunstancias, tales como factores climáticos, peligro de ataque de indios, convulsiones políticas internas, coyunturas de mercado, etc.

Según dicho itinerario, Mendoza distaba de Buenos Aires 261 leguas; el camino en cuestión, pasaba por San Luis, la cual estaba a unas 203 leguas del puerto. Su recorrido era bastante dificultoso, dados los desiertos y ríos a atravesar, y en ocasiones, peligroso, dependiendo del statu quo con los indios de la frontera sur. Todo ello hacía que entre los principales centros de la carrera de Cuyo se utilizaran distintas huellas alternativas según las circunstancias, las cuales volvían a juntarse al llegar a los puntos terminales. ${ }^{6}$

En cuanto a las características del camino, el tramo que más dificultades presentaba era la "travesía" desde San Luis a Corocorto, terrible de-

5 Braudel, Fernand: El Mediterráneo y el mundo mediterráneo en la época de Felipe II, México, 1953, t. 1, pág. 345.

6 Sobre itinerarios y distancias se puede consultar, entre otros, a Huertas, María Marta: "Los caminos de la frontera oeste argentina durante el período hispánico; segunda parte: Las vías de comunicación en el siglo XVIII", en Cuadernos del CEIFAR, n. ${ }^{\circ}$ 9, Mendoza, 1983. 
sierto de 32 leguas que, sobre todo en verano cuando el Desaguadero se secaba, era la tumba de innumerable cantidad de bueyes. Undiano y Gastelú escribió al respecto:

"la soledad del sitio, aquel retiro, aquel silencio, y la memoria de las mortandades acaecidas por falta de agua potable, tienen el ánimo en este melancólico lugar en una triste suspensión, a que sucede un vivo deseo de salir de él... [ y luego agrega] un terreno sequísimo y desigual alternado de lomas y cañadas, a trechos duros y a trechos arenosos: un camino malísimo para ruedas por haberle cortado y desfigurado las aguas de tormentas desde que le abandonaron los troperos, es lo que ofrece esta distancia a la vista del caminante". ${ }^{7}$

En ocasiones el viaje se dificultaba aún más pues el camino estaba obstruido por las osamentas de los animales de tropas anteriores, que debían ser movidas para dejar libre el tránsito. En época estival, este trayecto generalmente se hacía de noche para evitar las altas temperaturas diurnas. En invierno, se hacía muy difícil vadear el Desaguadero dada la creciente que presentaba; en esos casos, los viajeros debían cruzar el río a través de balsas. ${ }^{8}$ Desde Mendoza a San Juan había unas 45 leguas; sin embargo ese era un camino sólo utilizado por los escasos troperos sanjuaninos. Los arrieros preferían utilizar un sendero entre médanos (donde no había postas) que permitía una comunicación más rápida y directa entre San Juan y San Luis.

En cuanto a rutas complementarias, desde San Juan partía una hacia San Miguel de Tucumán (a 190 leguas), pasando por La Rioja (a 89 leguas) y Catamarca (a 131 leguas). Otro camino unía a Córdoba con San Luis (a 83 leguas) y un sendero para mulas, luego mejorado para permitir el paso de tropas de carretas, conectó a Córdoba con Catamarca.

De acuerdo al itinerario mencionado, Jujuy distaba de Buenos Aires 408 leguas, Salta 392, Tucumán 307, Santiago del Estero 267 y Córdoba 157. También en la carrera del Norte había alternativas a la ruta principal; ${ }^{9}$ la más importante era el camino "de los Porongos" que comunicaba a Santiago directamente con Santa Fe (a 93 leguas del puerto), permitía un ahorro de 80 leguas y, si bien recorría una región más despoblada, la misma era más llana en comparación con el áspero terreno cordobés. Otra de

7 Undiano y Gastelú, Sebastián de: "Itinerario de Mendoza a Buenos Aires por el camino de las postas, escrito en Mendoza en 1799", en Anuario de la Sociedad de Historia Argentina, v. 2, Buenos Aires, 1941, pág. 535.

8 Miers, John: Viaje al Plata (1819-1824), Buenos Aires, 1968, págs. 100-101.

9 En muchos casos, se evitaba pasar por algunas jurisdicciones para eludir los diversos impuestos al tránsito de los estados provinciales. 
las vías alternativas era la que unía a Santiago con Salta, sin pasar por San Miguel (camino "de Palomares" o "Thenené"), o la que conectaba a Córdoba y Santa Fe.

Las Salinas Grandes, situadas a poco más de 100 leguas al suroeste de Buenos Aires, eran objeto de visitas periódicas - generalmente una vez por año, aunque a veces se realizaban dos o más, pero también podían pasar hasta tres años (o más) sin que se hiciera ninguna- por parte de expediciones económico-militares, cuyos principales objetivos eran, por un lado, abastecer a la ciudad del preciado elemento, y por otro, ir consolidando la presencia del hombre blanco en una región que dominaría totalmente bien entrada la segunda mitad de la centuria. Según Lucio V. Mansilla, la ruta a las Salinas fue esencialmente un "camino indio", una rastrillada,

“...surcos paralelos y tortuosos que con sus constantes idas y venidas han dejado los indios en los campos...Estos surcos...suelen ser profundos y constituyen un verdadero camino ancho y sólido". ${ }^{10}$

\section{Los medios de transporte}

Uno de los medios de transporte más utilizado en las llanuras era la carreta; descrita ya innumerables veces, no parece necesario abundar sobre el tema; de cualquier modo, quizá fuera conveniente subrayar algunos aspectos relacionados con el mismo. Muchos viajeros, alguno de ellos citados en el presente trabajo, dejaron sus relatos sobre las características del vehículo en cuestión, pero es posible que ninguno sea tan minucioso como el de Florián Paucke - aun cuando el de Alonso Carrió de la Vandera, Concolorcorvo, sea, quizás, el más conocido-, quien describe desde el modo de engrasar las ruedas y ejes (para lo cual se empleaba sebo y paja quemada o directamente jabón del que "se usa para lavar") hasta la corneta que utilizaba el conductor (peón) de esta "choza viajante" para "animar a los bueyes" (generalmente cuatro o seis por cada carreta). ${ }^{11}$

10 Mansilla, Lucio V.: Una excursión a los indios Ranqueles, 8va. ed., Buenos Aires, 1962, pág. 24.

11 Paucke, Florián S.J.: Hacia allá y para acá; una estada entre los indios Mocobíes (17491767), Tucumán-Buenos Aires, 1942, t. 1, págs. 121-124; el jesuíta diferencia dos clases: las carretas propiamente dichas, para cargas, y los carretones "en que viajan por lo común las personas viajeras junto con su equipaje". Concolorcorvo: El lazarillo de ciegos caminantes, Madrid, 1980, págs. 126-129; éste, a su vez, diferencia a carretas y carretones por los materiales utilizados en su construcción: mientras los últimos eran totalmente de madera, la caja de las primeras eran de junco seco o totora entretejido, cubierto con cueros de toro cosidos. 
Respecto al número de carretas que conformaban un convoy, las fuentes consultadas indican que aquél podía variar desde una pequeña cantidad hasta la alineación de una larguísima caravana —esto último era conveniente si existía la posibilidad de un ataque indígena-, tal el caso de las expediciones a las Salinas, en donde podían llegar a intervenir hasta seis-

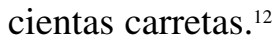

En cuanto a los bueyes, Concolorcorvo destaca "la resistencia de los bueyes rocines de Mendoza" y la valentía de los de Tucumán, que cruzaban caudalosos ríos, aun cuando las aguas les cubrieran prácticamente todo el cuerpo; Paucke, a su vez consideraba que un buen buey indiano podía llegar a tener "la fuerza de dos iguales en Alemania", pese a lo cual se necesitaban unos diez animales por cada carreta, para recambio y cubrirse en caso de que algunos sucumbieran. En ocasiones, cuando la dotación de bueyes de una carreta no era suficiente para avanzar, se utilizaban "cuartas"; según el "Lazarillo",

"éstas se reducen a hechar dos o tres bueyes más, que sacan de las otras carretas, y así se van remudando, y a la bajada, si es perpendicular, poner las cuartas en la trasera de la carreta para sostenerla y evitar un vuelco, o que atropelle y lastime a los bueyes pertigueros". ${ }^{13}$

No todos, sin embargo, eran tan considerados con estos animales; Bauzá y Espinosa, oficiales de la expedición de Malaspina, señalan que si los bueyes se cansaban en ocasión de recorrer trayectos desérticos, a menudo eran abandonados por los carreteros, para ser presas de la sed, el hambre y las aves de rapiña. ${ }^{14}$

Desde la región cuyana, el grueso del transporte lo llevaban a cabo las tropas de carretas de Mendoza y las recuas de mulas de San Juan, acarreando principalmente caldos (vino y aguardiente), frutas secas y, en ocasiones, productos ganaderos, en especial cueros vacunos. Desde las regiones Central y Norte del espacio, cuyos principales centros eran Córdoba, Santiago del Estero y Tucumán, el transporte se hacía por medio de carretas casi exclusivamente. De la primera venían productos ganaderos como cueros vacunos, cerda, lana y curtidos; también tejidos "de la tierra" (de lana), tales como

12 Martínez, Pedro Santos: Las industrias durante el Virreinato (1776-1810), Buenos Aires, 1969, pág. 125.

13 Concolorcorvo: El lazarillo..., pág. 136.

14 Haenke, Tadeo: Viaje por el Virreinato del Río de la Plata, Buenos Aires, 1943, pág. 34. 
ponchos, "frezadas" y jergas. De Santiago llegaba miel, cera, ponchos (de algodón) y cueros vacunos, y de San Miguel, maderas duras - recordemos que en Tucumán floreció la artesanía de construcción de carretas-, suelas y cueros vacunos, arroz, etc. Aun en el Litoral, donde se había implementado un relativamente eficaz sistema de transporte fluvial, el comercio interno dependía de las carretas, las cuales, dada la riqueza forestal, eran elaboradas en las carpinterías de la región, tal el caso de las correntinas. ${ }^{15}$

En cuanto a la capacidad de carga de los medios de transporte empleados en el Plata, una carreta podía acarrear unas 150 arrobas (@: equivalente a 11,50 kilogramos) y una mula unas $12 .{ }^{16}$ En ese sentido, nuestros datos indican que si bien la oferta de transporte por arrias es más elástica, su capacidad de acarreo es tan limitada que el grueso de la actividad del transporte terrestre depende de las tropas de carretas. Dicha elasticidad iba acorde a la inversión necesaria para la implementación de una recua, mucho más accesible para un campesino o un pequeño comerciante que la formación de un convoy de carretas. Mientras las arrias podían ponerse en marcha con unas cuantas mulas, dinero para salarios del capataz y peones, y alimentos para la travesía, la organización de una tropa de carretas implicaba mayores erogaciones: vehículos, boyada, caballada, dinero para salarios de varias clases de empleados (capataz, carpintero, picadores, boyeros, boyeros de invernada, etc.) y, en ocasiones, la invernada, alimentos, utensilios, etc. De todos modos, troperos ocasionales - tema sobre el que volveremos - podían aunar esfuerzos para marchar juntos (en especial cuando se trataran de distancias relativamente cercanas) y sortear más fácilmente los obstáculos que se presentaran en el camino. ${ }^{17}$

Hacia fines del período rosista, un gran número de carretas llegaba a los dos grandes mercados de concentración de Buenos Aires: Plaza Constitución y Plaza Once de Septiembre; Justo Maeso, editor y traductor de la obra de Woodbine Parish, cónsul británico en estas tierras, señala que durante 1851 y 1852 entraron, por año, alrededor de 1.000 carretas de Salta, Tucumán y Santiago del Estero, y 2.500 de Córdoba, cantidad que se iría reduciendo a medida que el ferrocarril se fuera expandiendo.

15 Chiaramonte, José Carlos: Mercaderes del Litoral. Economía y sociedad en la provincia de Corrientes, primera mitad del siglo XIX, México-Buenos Aires, 1991, pág. 78.

16 Hacia mediados de siglo, el viajero belga Alfred Marbais du Graty calculó una capacidad de carga un tanto mayor para ambas modalidades. Cfr. Urquiza Almandoz, Oscar F.: Historia Económica y Social de Entre Ríos (1600-1854), Buenos Aires, 1978, pág. 557.

17 En el cuadro 4, en el Anexo Estadístico, podemos encontrar algunos ejemplos puntuales sobre la cantidad de hombres, bestias y vehículos necesarios para organizar convoyes y recuas. 
Los fletes que se pagaban por arroba transportada en carreta, según el citado Maeso, eran los siguientes: desde Buenos Aires a Córdoba, 2 reales; a Santiago y San Miguel, 9; y a Salta, 13. El viaje desde las provincias costaba uno o dos reales menos, excepto en el caso cordobés, que era a la inversa. ${ }^{18}$

\section{La demanda de transporte por parte del Estado}

Durante la época hispánica eran frecuentes los contratos entre los transportistas y la Real Hacienda para el traslado de caudales y azogues, de reos, de prisioneros británicos durante las invasiones, de cascarilla, de pólvora, de hierro, de plomo, de armamentos, etc. Sin embargo, los carreteros (preferidos, obviamente, por la capacidad de carga de sus convoyes en tanto y en cuanto las características topográficas de las regiones a transitar lo permitieran) poco entusiasmo hallaban en esta clase de tarea, dadas las dificultades que tenían en cobrar sus servicios ante las trabas burocráticas implantadas por el aparato estatal. De todos modos, ya fuera que les gustase o no a los transportistas, el Estado tenía prioridad absoluta en la satisfacción de su demanda de transporte..$^{19}$

Poco después de producida la Revolución el panorama es bastante similar. Una carta de Manuel Belgrano al gobernador intendente de Salta, Feliciano Antonio Chiclana, es ilustrativa al respecto:

"Ni es fácil persuadirse que los comerciantes hayan sido los ocultadores de mulas, carretas y peones, y los que hayan entorpecido el envío de los pertrechos de guerra. Naturalmente los conductores deben preferir a aquél que les paga mejor o les ofrece mayores ventajas en la conducción, y esto basta para que ellos sin más estímulo ni otro móvil le prefieran ocultando de los demás las arrias, carretas y boyadas. Es constante que el Estado sólo les da a los troperos y arrieros el dinero necesario para su habilitación y gastos indispensables, y que el comerciante les paga lo que piden adelantándoles cuando menos la mitad o las dos tercias partes del flete, y por lo mismo sin otro influjo ni maquinación, el comerciante debe tener carretas careciendo de ellas el Estado". ${ }^{20}$

18 Parish, Woodbine: Buenos Aires y las provincias del Río de la Plata desde su descubrimiento y conquista por los españoles, traducción aumentada con notas y apuntes de Justo Maeso, estudio preliminar de José Luis Busaniche, Buenos Aires, 1958, págs. 369-370.

19 Sobre el transporte de tabaco se puede consultar a Arias Divito, Juan Carlos: "Transporte de tabacos y naipes, 1778-1812”, en Historiografía Rioplatense, n. ${ }^{\circ}$ 5, Buenos Aires, 1997, págs. 7-70.

20 Salta, 5 de marzo de 1813. Archivo General de la Nación (en adelante AGN), Biblioteca Nacional, doc. 5253 . 
Relacionado con este tema, hemos encontrado varias demandas por incumplimiento de pagos de fletes por parte del Estado. Al respecto, podemos mencionar el flete de 18 carretas desde Santa Fe a Buenos Aires, a 65 pesos cada una, para el transporte de camas de carreta y otro similar, de 13 vehículos, para el traslado de maderas varias, desde y hacia los mismos lugares. Otro, desde Buenos Aires a Tucumán, que involucraba a 12 carretas cargadas con 264 cajones de azogue a 190 pesos por unidad. Desde Mendoza se fletaron 12 carretas, a 100 pesos cada una, para el traslado de soldados; también desde Buenos Aires y hacia Tucumán partieron efectivos militares en 33 vehículos contratados a 180 pesos la unidad, y desde Santa $\mathrm{Fe}, 4$ carretas a un flete de 46 pesos cada una, transportaron tropas hacia Buenos Aires. Por último, para el traslado de pertrechos bélicos, se fletaron 9 vehículos en Buenos Aires con destino a Córdoba a 55 pesos cada uno. Generalmente, los troperos recibían sólo la mitad de lo estipulado y ello originaba las constantes demandas. ${ }^{21}$ Además de las conocidas trabas burocráticas, heredadas del régimen hispánico, se debe tener en cuenta que las arcas del Estado revolucionario estaban exhaustas.

\section{Movimiento general de tropas y arrias}

Un estudio realizado para $1820^{22}$ nos indica que el total de carretas movilizadas desde Cuyo fue de 160 unidades, unas 24.000 arrobas (@) transportadas, a las que se deben agregar 3.290 mulas, que acarrearon alrededor de $39.500 @$. Fueron, pues, unas 63.500 @ que llegaron a Buenos Aires, contra 117.000 de promedio del período tardocolonial (1781-1811). Las cifras son elocuentes: mientras que el número de mulas desplazadas fue el más importante de todo el lapso, el de carretas fue paupérrimo, muy lejos de los 700 y más vehículos que circularon en algunos de los años de la primera década del siglo XIX, y bien sabemos que el considerable aporte de las mulas movilizadas no alcanza para compensar el retroceso del transporte carreteril.

En cuanto a la cantidad de carretas por tropa, cada una de éstas estaba conformada, como media, por 8 unidades, contra 9 del período anterior; las arrias, por el contrario, fueron más numerosas que en el lapso 17811811 ( 25 y 21 bestias, respectivamente).

21 Todas las demandas son de 1814. Ver en AGN, III, 20-11-8 (entre guías 408 y 409); 20-119 (entre guías 461 y 462); 21-1-1 (entre guías 1349 y 1350, entre guías 1548 y 1549, y entre guías 1681 y 1682), y 21-1-2 (entre guías 2003 y 2004).

22 Ver el citado trabajo "Los transportes durante la primera década post-revolucionaria...". 
Por la carrera del Norte se desplazaron 260 carretas, unas 39.000 @ transportadas hacia Buenos Aires, bastante menos que las acarreadas desde Cuyo, a pesar de que desde esta última región salieron 100 vehículos menos; obviamente la diferencia fue marcada por la gran cantidad de mulas movilizadas desde Mendoza y San Juan. Las tropas norteñas estaban conformadas, como promedio, por 5 unidades, contra 6 que observamos, como media, para el lapso colonial.

Podemos afirmar que en lo que se refiere a la movilización de personas y recursos, en 1820 la carrera de Cuyo aparece como más significativa que la del Norte. De todos modos, las dos carreras juntas - lo que podría considerarse el transporte terrestre- están lejos de superar a la que durante el lapso colonial se llamó la carrera del Paraguay —es decir, el transporte fluvial — ${ }^{23}$, a pesar del aislacionismo de esta última, que redujo el total transportado a unas 135.000 @, y ello sin tener en cuenta lo acarreado a través del río Uruguay. Entre 1781 y 1811 por las carreras del Paraguay, de Cuyo y del Norte - en orden de importancia - se transportaron, como promedio, casi 400.000@; en 1820, la cifra bajó a poco más de 237.000 @, manteniéndose el orden de importancia.

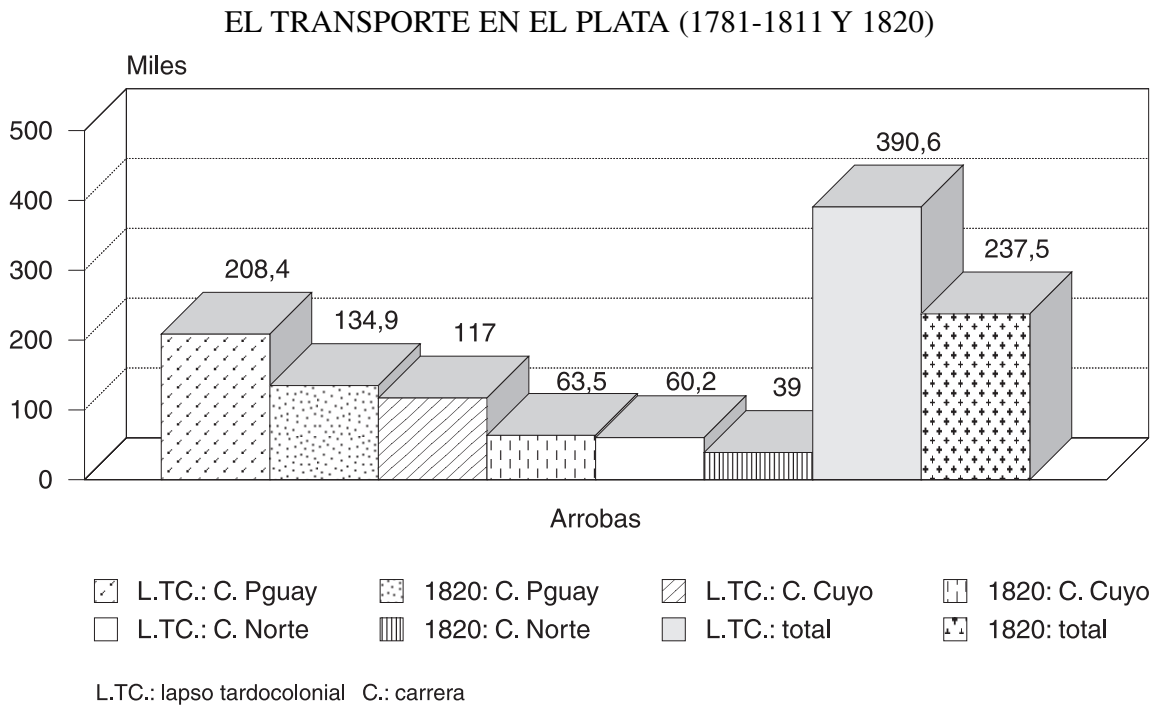

23 Son apreciables las ventajas del acarreo fluvial dadas la capacidad de carga de las distintas naves, la baratura de sus fletes y la velocidad de desplazamiento. Sobre el tema se puede consultar a Chiaramonte: Mercaderes del Litoral..., págs. 78-81. 
La situación de 1820, como hemos visto, pálido reflejo de lo que sucedió durante el lapso tardocolonial, se verá trastocada con el correr del tiempo. Diez años más tarde, a la vez que el esplendor vitivinícola cuyano era una cosa definitivamente del pasado (al menos, en el marco de las relaciones de producción que se establecieron durante la colonia), los bienes "de la tierra" de Córdoba, Santiago del Estero y Tucumán, en especial la riqueza ganadera de la primera, volcará la balanza a favor de la carrera del Norte.

También hemos recogido información sobre el tema en el Registro Estadístico de la Provincia de Buenos Aires para los años 1822-1824 . ${ }^{24}$

En principio, debemos decir que hemos notado ciertas diferencias entre la información de los resúmenes anuales y la consignada en forma mensual, trimestral o semestral a lo largo del trienio; nos hemos guiado por la última dado que es más detallada.

En cuanto a las entradas, el resumen de 1822 indica que "desde marzo que se empezó a llevar la razón correspondiente, han entrado en esta ciudad de las provincias hasta fin de diciembre 111 tropas..., y 190 arrias de mulas"; sin embargo, entre las primeras están incluidas 9 que lo habían hecho en enero y febrero, y entre las segundas no lo están 2 que habían arribado a comienzos del año, por lo que en realidad suman 192. La información de dichos meses sólo ilustra sobre el número de tropas y arrias, su procedencia y la cantidad de peones que sirven en las tropas. Del segundo semestre de 1824, solamente sabemos cuanto suman los convoyes y las recuas, el origen de los mismos y la carga que trasladaron.

Respecto a las salidas, no se encuentran los datos de enero y febrero de 1822; además, 19 arrias que parten "vacías" en el mes de abril, y en donde no se contabilizan peones ni bestias, son excluidas en la suma general. En el resumen de 1823 falta registrar dos arrias; en fin, dada la gran cantidad de recuas que retornaban "vacías", lo que se puede observar al analizar el peso de la carga transportada por las mismas en 1822, no es extraño que la información correspondiente a los dos años siguientes, prácticamente fuera desechada. Una vez más, los datos del segundo semestre de 1824 son parcos: sólo indican la cantidad de tropas, el destino y la carga transportada. Por último, el resumen de ese año consigna la salida de 33 tropas, pero en la información desagregada por semestres computamos sólo 32.

Si bien no se especifica la procedencia y el destino de algunas tropas y arrias, la fuente indica que, de ellas, la mayoría de las primeras transita-

24 Ver el apartado sobre las Fuentes y el Anexo Estadístico al final del trabajo. 
ron la ruta norteña, y que la totalidad de las segundas lo hicieron por la que unía a Buenos Aires con Cuyo.

La carga está expresada en arrobas (@) - tal como aparece en los datos mensuales, trimestrales o semestrales consultados-, si bien en los resúmenes de 1822 y 1824 lo está en quintales.

El Registro Estadístico del Estado de Buenos Aires de 1856 a 1858, (similar a su antecesor de la década del 20, al menos en cuanto a la información sobre el movimiento general del transporte), brinda datos correspondientes a los años 1828-1831, si bien son bastante más incompletos que los del trienio estudiado. ${ }^{25}$

Sobre las entradas del primero de los años citados, una nota aclaratoria expresa que "no se han recibido los datos pertenecientes al mes de diciembre"; otra, esta vez sobre las salidas, indica que "no se han recibido las razones de los meses de abril y diciembre" y, además, no hay registrada información de partida de arrias.

La situación se repite en los años siguientes. De 1829, no se consignan datos de entrada de tropas de abril a junio, y de entrada de recuas durante los meses de febrero, mayo a septiembre y los dos últimos del año; tampoco hay cifras de salidas de convoyes de marzo a julio, y faltan las de arrias para todo el año.

Los dos años restantes están aún más incompletos. En los cuadros de 1830 aparece la siguiente nota: "El Departamento Estadístico no ha podido llenar los datos de esta tabla por haber faltado con ellos los comisionados para remitírselos" y, finalmente, en 1831 se indica que "además de estar incompletos los datos que se expresan, el Departamento Estadístico no ha recibido las relaciones que deben remitírsele para el lleno de esta tabla".

En síntesis, si bien la información sobre el cuadrienio es fragmentaria, nos sirve para ilustrar de manera muy general la cuestión

Por último, tres trabajos sobre el comercio entre Buenos Aires y las provincias durante el lapso rosista utilizan la Gaceta Mercantil como fuente principal para tratar el tema de las entradas y salidas terrestres.

Lamentablemente, la fuente en cuestión es bastante limitada, de lo cual están conscientes al menos algunas de las autoras de los artículos, pues en uno de ellos se aclara "que no cuenta con datos regulares ni con el precio de los productos o monto total de las cargas". ${ }^{26}$ 
A través de los datos extraídos de dichos trabajos hemos confeccionado el cuadro 3 (ver en el Anexo Estadístico) que merece ciertos comentarios. En principio, casi no hay datos de salida de arrias. La entrada de tropas de 1836 y 1837, y la de arrias del primero de los mencionados, está sólo estimada; además, no se dan datos de entradas de arrias para 1839. Sólo en el primer estudio, sobre el lapso 1830-1835, se desagregan cifras según procedencia y destino de los transportes: Córdoba era la provincia que mayor cantidad de convoyes enviaba y recibía, y desde San Juan llegaba el mayor número de recuas; para los años posteriores la información es muy general, aunque confirmaría la tendencia señalada. ${ }^{27}$

\section{Los hombres del transporte}

El análisis de los nombres de los transportistas aparecidos en las Guías y Manifiestos de comercio conservadas en el Archivo General de la Nación, ${ }^{28}$ nos llevó a la conclusión de que el grueso del acarreo está a cargo de profesionales, si bien son un porcentaje menor del total.

Junto a ellos están los que podrían ser clasificados como estacionales, sujetos cuya profesión no era la del transporte sino que posiblemente se dedicaran a las tareas rurales y que en los lapsos de menor trabajo o inactividad acercaran al mercado porteño frutos de su propia producción, para aumentar de esta manera el ingreso familiar. De todos modos, a través de las fuentes nos resulta muy difícil de detectar esta clase de transportistas.

Lo que sí hemos comprobado es la existencia de - lo que podríamos llamar- transportistas ocasionales, aquellos que circunstancialmente hacían un viaje y no volvían a repetir la experiencia, o lo hacían muy contadas veces. Según nuestros datos, alrededor del $70 \%$ de los hombres del transporte podrían situarse dentro de esta última categoría. ${ }^{29}$

En términos generales, entonces, podemos clasificar a los transportistas en profesionales y ocasionales, aunque resulta dificultoso determinar qué número exacto pertenece a una u otra categoría; una forma de acercarnos al problema fue establecer una división sobre la base de la cantidad de viajes emprendidos desde las regiones del interior del espacio rioplatense

27 Otro interesante estudio que nos ilustra sobre el movimiento carreteril de la época es el de Palomeque, Silvia: "Circulación de carretas por las rutas de Santiago (1818-1849) (elementos cuanti-

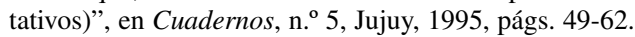

28 Los años analizados fueron 1820, 1831-1835 y 1839-1851; ver el apartado sobre las Fuentes.

29 Palomeque, no obstante las dudas que plantea en su estudio, parecería corroborar este fenómeno de la ocasionalidad. Cfr. Palomeque: "Circulación de carretas...", pág. 59. 
durante el período en estudio. ${ }^{30}$ En efecto, aquéllos que se desplazaron cinco veces o más, fueron considerados dentro de la primera categoría y los que realizaron de uno a cuatro viajes fueron englobados dentro de los ocasionales; a éstos habría que agregarles aquellos transportistas que, según nuestros registros, sólo viajaron (en una o más oportunidades) en 1820.

\title{
Los carreteros cuyanos
}

Hemos contabilizado 95 troperos que transitaron la Carrera de Cuyo:

54 ocasionales ${ }^{31}$

33 profesionales

8 del año 1820 ,

siendo uno de ellos de sexo femenino. ${ }^{32}$

La distribución regional de los carreteros es la siguiente:

\author{
74 de Mendoza \\ 8 de San Juan \\ 12 de San Luis \\ 1 de Río Cuarto (Córdoba).
}

Nuestros datos indican que 25 de ellos también acarrearon productos regionales cuyanos por medio de sus propias arrias de mulas y que 35 transitaron por las dos carreras, es decir, la de Cuyo y la del Norte.

Respecto a la totalidad de los viajes de sólo los troperos identificados, hemos contabilizado 19 para 1820 y 280 más entre 1831 y 1851; el hecho de que en las fuentes no se encuentren viajes desde Chile, coadyuva a entender las bajas cifras obtenidas sobre viajes - aun sumando los de los arrieros, tema que después veremos-, en relación con el lapso colonial, cuando el promedio de los mismos superaba los 100 anuales..$^{33}$

30 Hay casos de transportistas de los que ya teníamos noticias por las investigaciones sobre el tema para $1781-1811$.

31 Uno de ellos, Simón Astorga, está sólo “a cargo" de una tropa en 1845.

32 Se trata de doña Candelaria Sosa, probablemente viuda de Casillas, tropero fallecido hacia mediados de la década del ' 40.

33 Si bien Chile parece mantener exiguos vínculos con la antigua capital virreinal, hay que tener en cuenta, sin embargo, que — tal como señala Wentzel— a partir de 1819 Chile pasa a tener el status de "puerto extranjero" y las guías correspondientes al comercio con dicha zona se encuentran en los libros de entradas y salidas marítimas; para este período habría sido más importante, entre Chile y Buenos Aires, la conexión a través del Cabo de Hornos que la terrestre. Cfr. Wentzel, Claudia: "Reconsideraciones sobre el comercio interno de Buenos Aires de 1809 a 1821”, (mimeo), 1987, pág. 7. 
Los carreteros que más viajes realizaron fueron:

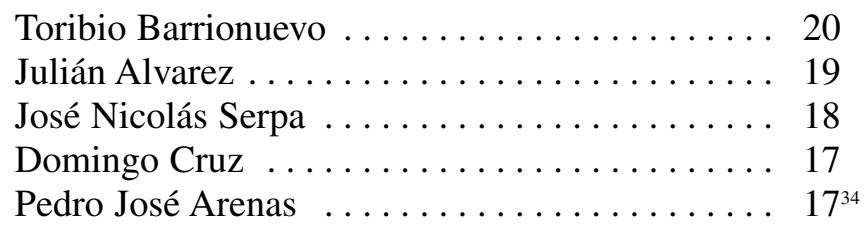

En cuanto a la frecuencia de viajes, de los 54 ocasionales, 8 hicieron por lo menos dos viajes en alguno de los años del estudio; de los 33 profesionales, 16 viajaron más de una vez (hay casos de más de uno o dos viajes en varios de los años del análisis) y los otros 17 completaron dos o más considerando la otra carrera, su desempeño como arriero o el lapso hispánico, excepto un tropero, Gregorio Ponce.

Entre los que más se destacaron por la frecuencia de viajes podemos mencionar a los realizaron dos o más viajes en, por lo menos, 5 años de los que abarca nuestro trabajo: Pedro Juan Alvarez, Dionisio Guerreros y José Nicolás Serpa y los que lo hicieron en 6 años: Julián Alvarez, Pedro José Arenas y Domingo Cruz; pero sin duda el más caracterizado fue Toribio Barrionuevo, que lo hizo en 7 años, y en 3 de los mismos completó tres viajes.

El análisis de la velocidad de los viajes comerciales se hizo para 1820 y del resto del lapso en estudio no hemos hallado datos para buena parte del mismo; en el mejor de los casos sólo tenemos cifras parciales para algunos de los años, por lo que hemos escogido 1832 como el más representativo. Debemos recordar que el tema de la frecuencia y velocidad de los viajes está íntimamente relacionado con el de la rotación del capital comercial.

La velocidad de las tropas de carretas en 1820, si bien hallamos sólo 15 casos como para extraer una conclusión definitiva, decrece: 58 días contra diez menos (en los viajes desde Mendoza) que se utilizaban, como promedio, en el período tardocolonial.

En este sentido, los ataques de indios, "montoneras" y bandoleros parecería haber afectado el normal desplazamiento de los transportistas mendocinos. Al respecto, es ilustrativo el "Manifiesto de la Honorable Junta de Representantes de la Provincia de Buenos Aires a todas las demás hermanas":

34 A estos habría que agregarles el viaje que como arrieros realizaron Barrionuevo y Arenas, más los que sumaron - 16 en total— los cinco troperos por la ruta del Norte. 
"La guerra civil existe, y existe con encarnizamiento. Ya las caravanas de comercio que poco antes cruzaban todos los caminos del interior, repartiendo entre los pueblos la vida y la riqueza, hoy son escuadrones armados de hierros fratricidas, consagrados sólo a la matanza y al pillaje. Esto se verifica principalmente en el territorio de esta provincia, pero sus resultados arruinan a todas las demás". ${ }^{35}$

En 1832, sobre 13 casos los troperos de Mendoza tardaron 50 días para llegar desde su provincia a Buenos Aires; sobre 2 desde San Juan, uno directo y el restante pasando por Mendoza, los viajes duraron 44 y 74 jornadas, respectivamente. Desde San Luis, para 7 casos, se emplearon 35 días.

\section{Los arrieros}

En cuanto a los muleros, hemos sumado un total de 637 , todos del área cuyana:

$$
\begin{aligned}
& 501 \text { ocasionales }(79 \%) \\
& 63 \text { profesionales }(10 \%) \\
& 73 \text { del año } 1820(11 \%)
\end{aligned}
$$

De todos modos, entre los ocasionales se encuentran 20 que no son dueños de recuas; 17 viajaron como capataces y 3 "a cargo". ${ }^{36}$

La distribución regional es la siguiente:

$$
\begin{aligned}
& 220 \text { de Mendoza (35\%) } \\
& 415 \text { de San Juan (65 \%), }
\end{aligned}
$$

a los que habría que agregarles 2 oriundos de San Luis.

35 Buenos Aires, 28 de septiembre de 1820. Cfr. Segreti, Carlos S. A.: El país disuelto; el estallido de 1820 y los esfuerzos organizativos, Buenos Aires, 1982, págs. 224-225. También Schmidtmeyer observó un panorama similar: "Debido al estado de perturbación del país, a la declinación de su comercio interior, encontramos muy pocos viajeros o tropas de carretas; ... y a menos que algún cambio mejor tenga lugar en estas provincias, el intercambio puede llegar a ser todavía menor, más a causa de la falta de paz y seguridad que de objetos para comerciar". Cfr. Schmidtmeyer, Peter: Viaje a Chile a través de los Andes, Buenos Aires, 1947, pág. 177. De todos modos, en el caso cuyano, la guerra civil habría afectado significativamente su producción vitivinícola; ver Amaral, Samuel: "Comercio libre y economías regionales. San Juan y Mendoza, 1780-1820", en Jahrbuch für Geschichte von Staat, Wirtschaft und Gesellschaft Lateinamerikas, Band 27, Köln, 1990, págs. 1-67 y Wentzel: "Reconsideraciones...", págs. 38-39.

36 Vicente Lara viajó dos veces como capataz y los 16 restantes una sola vez, lo mismo que los 3 "a cargo". Pedro Guevara viajó una vez al frente de su recua y otra como capataz; Nicolás Gil lo hizo en diez oportunidades, tres de las mismas como capataz. 
El total de viajes de los arrieros cuyanos alcanza 116 para 1820 y 1162 para el lapso posterior; entre los muleros más destacados se encuentran:

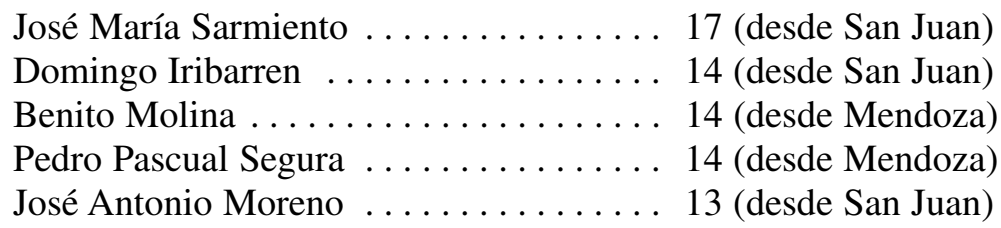

Respecto a la frecuencia de viajes, de los 501 ocasionales, 32 realizaron dos viajes en alguno de los años del lapso en cuestión y 1 lo hizo en tres oportunidades. De los 63 profesionales, 53 viajaron dos veces o más en alguno de dichos años. ${ }^{37}$ En cuanto a los 73 del año 1820, 14 completaron dos (o más) viajes en dicho año.

La frecuencia de viajes es menos notoria entre esta clase de transportistas; aun así hemos consignado a Melitón Arroyo y Benito Molina (ambos de Mendoza) y a Domingo Iribarren y José Antonio Moreno (los dos de San Juan) con dos o más viajes en 4 años del período en estudio, a Pedro Pascual Segura (de Mendoza) que lo hizo en 5 años y a José María Sarmiento (de San Juan) que lo llevó a cabo en 7 de los años que abarca nuestro análisis.

En cuanto a la velocidad de los viajes, en 1820 los arrieros mendocinos parecen sufrir los mismos inconvenientes que sus colegas carreteros: tardan bastante más que durante el lapso colonial, 52 contra una media de 46 jornadas. Andrés Villanueva, que conducía 45 cargas de aguardiente y vino, es obligado a detenerse en el paraje Barranquita, jurisdicción de Córdoba, durante dos meses, produciéndose una considerable merma en los caldos, al punto de perder 7 cargas, lo que motiva una investigación del caso. El peón Anacleto Balmaceda, natural de Mendoza, en su versión de los hechos, precisa

"que oyó decir que por el Señor General San Martín se había dado orden que parasen todas las tropas que fuesen llegando, porque no se podía pasar para esta ciudad, por estar los caminos ocupados por los montoneros...". ${ }^{38}$

37 Del resto, Plácido Maradona completó dos viajes en 1811 y los otros 9 no lograron realizar dos viajes en alguno de los años del lapso.

38 AGN, III, 22-1-2, guía 65. Problemas similares se exponen en la guía 101 y en III, 22-1-3, guías 484, 503, 514, 555 y 560; III, 22-1-4, guías 685, 686, 760 y 803; III, 22-2-9 (1821), guías 209 y 222; III, 22-2-10 (1821), guía 649. En cuanto a ataques de indios, puede verse III, 22-1-4, guías 777, 801 y 843; III, 22-2-9, guía 158. Al parecer los transportistas también sufrían los embates del bandolerismo; ejemplos de lo mencionado pueden ser las denuncias observadas en III, 22-1-2, guías 190 y 252. En todo caso, montoneras donde ocasionalmente confluían "anarquistas", indios y malhechores de todo 
Sin embargo, el caso de las arrias sanjuaninas es bien distinto: mientras que el promedio de 1781-1811 fue de 51 días para cubrir la distancia entre San Juan y Buenos Aires, en 1820 sólo se tardaron 45, y estos muleros también sufrieron los problemas de sus colegas mendocinos...; de cualquier modo, la "performance" del año 20 fue similar al de 1811, cuando se dio la mayor velocidad del período anteriormente estudiado, lo que podría indicar que hacia fines de la época colonial-principios de la independiente se comenzó a transitar una ruta más directa entre San Juan y Buenos Aires.

Para 1832, los arrieros mendocinos, sobre 12 casos, tardaron 55 días y los sanjuaninos, sobre 35, emplearon 46 jornadas. Desde San Luis, sobre 5 casos, los viajes duraron 28 días.

\section{Los carreteros del Norte}

En cuanto a los troperos de la ruta norteña, hemos contabilizado 442:

$$
\begin{aligned}
& 333 \text { ocasionales }(75 \%) \\
& 83 \text { profesionales }(19 \%) \\
& 26 \text { del año '20 }(6 \%)
\end{aligned}
$$

De los 333 ocasionales, hay 4 capataces y otros 4 "a cargo" con un solo viaje en el lapso. ${ }^{39}$ También entre los carreteros norteños encontramos a una mujer. ${ }^{40}$

La desagregación según áreas regionales es la siguiente:

$$
\begin{aligned}
& 11 \text { de Salta }(2 \%) \\
& 91 \text { de Tucumán }(21 \%) \\
& 70 \text { de Santiago del Estero }(16 \%) \\
& 269 \text { de Córdoba }(61 \%) ;
\end{aligned}
$$

el restante es de Jujuy.

\footnotetext{
tipo, perturbaban el normal desplazamiento y la vida misma de la campaña. Testimonios de estos hechos se pueden encontrar en el citado Schmidtmeyer, Peter: Viaje a Chile..., págs. 153-154 y 199-204. Haigh, Samuel: Bosquejos de Buenos Aires, Chile y Perú, Buenos Aires, 1918, págs. 51-52, 185 y 194. También encontramos testimonios en décadas posteriores. Cfr. Campbell Scarlet, Peter: Viajes por América. A través de las Pampas y los Andes, desde Buenos Aires al Itsmo de Panamá, Buenos Aires, 1957, págs. 51, 77-79 y 85-86. Gerstaecker, Frederich W. C.: “Mendoza en el año 1849”, en Revista de la Junta de Estudios Históricos de Mendoza, 2. 'época, n. ${ }^{\circ}$ 8, t. 1, Mendoza, 1975, pág. 517.

39 Uno de ellos, Manuel Arias, es tropero cuyano.

40 Se trata de doña Tomasa Gondra de Santillán.
} 
Los viajes de los troperos norteños alcanzaron la cifra de 39 en 1820 y 1365 en las décadas del ' 30 y siguientes. Si bien la cantidad de viajes en 1820 está lejos de la media colonial, los guarismos correspondientes a los decenios rosistas se acercan bastante al promedio del lapso tardocolonial, aun teniendo en cuenta que no se registran viajes desde el Alto Perú (Bolivia).

Varios transportistas, especialmente los cordobeses, se destacaron por la cantidad de viajes realizados:

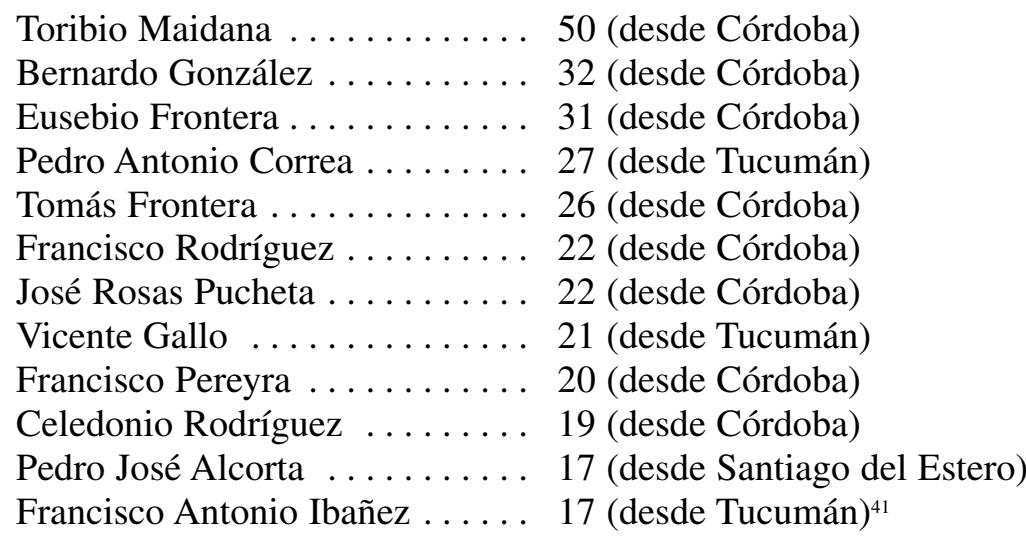

Sobre la frecuencia de viajes, podemos señalar que sólo 24 ocasionales hicieron dos viajes en alguno de los años del estudio y que solamente 9 de los profesionales no pudieron completar tal tarea, aun teniendo en cuenta viajes desde Santa Fe, tema que abordaremos más adelante; de los 26 del año 1820, 3 realizaron dos viajes durante el mencionado año.

Como hemos visto, varios troperos profesionales se destacaron por la cantidad de viajes llevados a cabo, especialmente los cordobeses; sin duda en ello influyó mucho la menor distancia a recorrer hasta la Aduana porteña y la bonanza productiva de Córdoba con relación al resto de las provincias interiores. Mencionaremos sólo a tres transportistas: Eusebio Frontera, con dos o más viajes en, al menos, 10 años del lapso estudiado (en 6 de dichos años realizó hasta tres viajes), Bernardo González, que los hizo durante 12 años (y en 5 de los mismos completó tres) y Toribio Maidana, que los llevó a cabo en 16 años (en 7 de ellos finalizó tres, y en 5 , cuatro viajes).

41 González realizó también un viaje desde Rosario e Ibañez dos desde Santa Fe. 
El estudio de la velocidad de los viajes para 1820 indica que es indudable que los mismos problemas que sufrieron los transportistas cuyanos, afectaron a sus colegas del norte, si bien las fuentes son menos ilustrativas al respecto: ${ }^{42}$ la velocidad de los viajes disminuye, y en mucho. De los 60 días que se tardaban — como promedio - desde Tucumán durante el período colonial, se pasa a 79; para Santiago del Estero (55 y 85, respectivamente) y Córdoba (34 y 53, respectivamente) sucede algo similar. Sin embargo, las trabas que impidieron el normal desplazamiento de las tropas norteñas parecerían no haberse manifestado hasta la segunda mitad del año en estudio. En efecto, durante la primera, los carreteros circularon incluso un poco más rápido que en el período colonial. ${ }^{43} \mathrm{~A}$ partir del segundo semestre, el sistema, ya de por sí alterado, se termina de desquiciar; que se tarden cuatro meses y más desde Córdoba, ilustra perfectamente el panorama. ${ }^{44} \mathrm{Al}$ respecto, las vicisitudes que debió sufrir José Antonio de Arriaga, vecino de Cochabamba, socio de Ambrosio Funes, a su vez vecino de Córdoba, iluminan sobre los riesgos a que se exponía el comercio de la época:

"habiendo dicho don Ambrosio remitido a Santiago de Chile una partida de curtidos para su expendio, por un orden inesperado de sucesos ha tenido que sufrir este negocio los contrastes más azarosos. No bien acababa de llegar a su destino esta desgraciada negociación, cuando en aquellos mismos días llegó a Santiago la noticia de la derrota que había padecido el ejército de la Patria en la memorable acción de Talca. Era demasiado peligrosa la suerte de aquella capital para que se creyesen seguras estas propiedades. El temor bien fundado de que fuesen unos de los despojos del enemigo, obligó al encargado del negocio a que tomase el duro partido de exportarlos precipitadamente a la ciudad de Mendoza. Como la gloriosa acción de Maipo dejó tranquilizado aquel estado, tomó la negociación su giro natural, y volvieron los efectos a ponerse en Santiago. Aquí empezó de nuevo a experimentar los malos resultados a que están expuestos los efectos del tráfico, porque abarrotada la plaza, estuvie-

42 AGN, III, 22-1-3, guía 611 y III, 21-4-5 (1816), guías 220 y 375; estas últimas ilustran sobre un sangriento ataque indígena. La queja de los viajeros ante el peligro de salteadores e indios es bastante recurrente. Cfr. Andrews, Joseph: Viaje de Buenos Aires a Potosí y Arica en los años 1825 y 1826, Buenos Aires, 1920, pág. 28. Aún en la década del '50 encontramos amargos relatos. Cfr. Tschudi, Johann Jacob von: "Viaje por las cordilleras de los Andes de Sudamérica; de Córdoba a Cobija en el año 1858”, en Boletín de la Academia Nacional de Ciencias, t. XLV, Córdoba, 1966, pág. 330.

43 Sobre 9 casos desde Tucumán, se tardaron 57 días; sobre 2 desde Santiago del Estero, 46; y sobre 24 desde Córdoba, 31 jornadas.

44 Nos sólo durante 1820 existieron inconvenientes para transitar: "los artículos siguientes que con procedencia de Córdoba fueron conducidos en tropa de D. Mariano Cuevas con destino a ésta, y por las circunstancias del país fue indispensable descargarlos en la villa del Rosario por hallarse privado el tránsito". AGN, III, 24-6-1, Buenos Aires, 6 de noviembre de 1840, f. 13. 
ron los curtiembres detenidos mucho tiempo. Esta fue la ocasión en que se formó mi compañía con el expresado don Ambrosio, y en la que me vi en la precisión de cambiarlos por tabaco negro del Brasil y trasladarlo para su salida a esta capital. La desgracia seguía siempre muy de cerca sus pasos. Puesta la tropa conductora en la jurisdicción de Córdoba, me hallé con la novedad de estar el camino interceptado por los movimientos anárquicos de los montoneros, y en la precisión de suspender la marcha por algunos meses con los costos y perjuicios que son irreparables de una demora tan considerable...".

Y aquí terminamos con la extensa cita, que sigue, pues los infortunios del pobre Arriaga no finalizaron al llegar a Buenos Aires: si bien pudo salvar sus bienes de guerras y montoneras, lo esperaban conflictos arancelarios con la Aduana porteña. ${ }^{45}$ En fin, sin duda la de comerciante podía llegar a ser una profesión bastante entretenida.

Volviendo sobre el tema de la velocidad de los viajes comerciales, debemos tener en cuenta, en cualquier caso, que nuestras cifras son aproximativas, que se trata de promedios y que, en ocasiones, contamos con muy pocos casos, lo cual puede distorsionar un tanto la situación.

En 1832, sobre 14 viajes de Tucumán, 7 de Santiago del Estero y 49 de Córdoba, se tardaron 67, 55 y 36 días, respectivamente. ${ }^{46}$

\section{Los carreteros de Santa Fe}

En cuanto a los viajes desde la jurisdicción de Santa Fe, sumaron 124 y fueron realizados entre 1839 y 1847 . Es interesante destacar que no hemos hallado ninguna conexión Santa Fe-Buenos Aires por vía terrestre antes o después de dicho lapso. Obviamente, la comunicación fluvial resultaba más barata, más cómoda y más rápida, pero el análisis de los viajes por tierra nos indica que más del $70 \%$ fue realizado en años de bloqueo, cuando la navegación se hacía muy dificultosa o definitivamente imposible.

De los carreteros que trajinaron la ruta Santa Fe-Buenos Aires, podemos indicar que hallamos 87

57 ocasionales

30 profesionales.

45 AGN, III, 22-2-9, guía 222.

46 Pedro Antonio Correa tardó 61 días de Tucumán, y 27 desde Córdoba; Mauricio Argañaraz empleó 72 desde Santiago del Estero y 44 desde Córdoba. 
De ellos, 8 transitaron por las carreras de Cuyo y del Norte, 2 sólo por la primera y 37 solamente por la segunda. ${ }^{47}$

Los que más realizaron fueron Santiago Aráoz, Javier Maidana -al parecer, el único santafesino-, Francisco Pereyra y Gregorio Ponce (4 viajes) y Juan José Arenas, Pedro Costas, Pedro Luque y Antonio Maison (3 viajes).

Tan sólo 5 de los ocasionales y 10 de los profesionales realizan más de un viaje en alguno de los años del período analizado; el resto de los integrantes de la segunda categoría completan más de uno en alguno de dichos años desde otras regiones.

\section{Conclusiones}

Los transportistas terrestres rioplatense, dada la incapacidad estatal para solucionar los problemas viales existentes,${ }^{48}$ en no pocas oportunidades se ocuparon del mejoramiento de los caminos, a la vez que estuvieron siempre dispuestos a buscar nuevos itinerarios que fueran más cortos y/o cómodos, y también menos peligrosos. Una idea de libertad de tránsito, fuertemente arraigada, se iba plasmando en la práctica, lo cual no nos permite pensar en distancias interurbanas rigurosamente establecidas.

Desde Cuyo, tropas mendocinas y arrias sanjuaninas se encargaban del grueso del acarreo regional, del mismo modo que las carretas tucumanas y, en especial, las de Córdoba, atendían los requerimientos de las áreas central y norteña.

El fenómeno de la ocasionalidad del transporte parece haberse acentuado con el correr de las décadas; aun así, la mayor parte de la actividad estaba en manos de transportistas profesionales, los cuales, además, debían responder ante las necesidades de transporte por parte del Estado de forma prioritaria.

En cuanto a la velocidad del transporte, sólo era posible incrementarla a través de mejoras técnicas (que no abundaban) y la búsqueda de nuevas rutas más directas; la limitación que significaba la capacidad de carga de los medios de transporte, hacía impensable el traslado de menor peso en en 1846.

47 Anastasio Cuestas Ramallo, tropero de Córdoba, viene "a cargo" en su viaje desde Santa Fe

48 Aun en fechas tan avanzadas como 1855-1856, se pueden hallar reclamos sobre caminos defectuosos y falta de puentes a lo largo y ancho del territorio rioplatense. (Informes de los directores de las Mensajerías Nacionales, Juan Rusiñol y Joaquín Fillol). Cfr. Urquiza Almandoz: Historia Económica..., pág. 555. 
aras de un aumento de la velocidad. Conectado con el tema de la velocidad está el de la frecuencia de viajes; en ese sentido, los transportistas profesionales, generalmente más rápidos, estaban en condiciones de realizar más de un viaje por año. Desde Mendoza y Córdoba, por ejemplo, se podían completar, anualmente, de tres a cuatro viajes.

En comparación con el período tardocolonial es indudable que en 1820 el transporte sufrió un retroceso en varios de los rubros que hemos analizado (cantidad de viajes; número de tropas y vehículos; velocidad; carga transportada) $)^{49}$ y el panorama es similar en cualquiera de las carreras estudiadas. Sólo en el número de arrias y mulas que vienen desde Cuyo se nota algún incremento, el cual no pudo compensar el retroceso sufrido por el sistema de transporte a través de tropas de carretas.

Tal como sucedió durante la época hispánica, en 1820 —aunque en menor escala - la carrera de Cuyo aparece como más significativa que la del Norte en cuanto a la movilización de personas y recursos; sin embargo, dicha situación sufrirá cambios en las décadas siguientes de la mano de la bonanza económica de las áreas mediterráneas, en especial Córdoba y su significativa producción ganadera.

En síntesis, el sistema de transporte terrestre implementado en el espacio rioplatense se enfrentó, hasta la llegada del ferrocarril, a distintas dificultades — dilatadas distancias, inexistentes o precarias vías de comunicación llenas de obstáculos, mercados muy dispersos-. Si bien esto entorpecía el logro de una adecuada integración, tal sistema, conformado por rústicas tropas de carretas y sencillas recuas de mulas, permitió una relativa fluidez en la circulación de personas y recursos entre las diversas y distantes áreas del Río de la Plata.

\section{Las Fuentes}

Indagar sobre los sistemas de transporte de antaño es sin duda una tarea bastante compleja dadas la fragmentación y la dispersión de las fuen-

49 Respecto a los fletes, no hemos hallado demasiado datos por lo que nos resulta difícil establecer el comportamiento de los mismos, aunque sin duda tendieron a subir por los riesgos que corría el comercio en esos azarosos días; sin embargo, el caso particular de la conexión Buenos Aires-Chile vía Cuyo se habrán de sentir en esta última región los efectos negativos de la utilización de los fletes marítimos a través de la ruta del Cabo de Hornos. Cfr. Schmidtmeyer: Viaje a Chile..., pág. 184; Wentzel: "El comercio del 'Litoral de los Ríos' con Buenos Aires: el área del Paraná, 1783-1821”, en Anuario del IEHS, n. ${ }^{\circ}$ 3, pág. 198. 
tes que pueden ilustrar sobre la cuestión. Obstáculos similares se nos habían presentado cuando emprendimos el estudio del transporte durante la época hispánica. Sin embargo, aquellas dificultades se vieron agravadas al tratar el tema en el período post-revolucionario, en especial a partir de la década del '20, pues con la reforma administrativa de la provincia de Buenos Aires, desapareció la alcabala, una herramienta por demás útil para el análisis del problema. El examen de las Guías de comercio - a partir de las cuales se cobraba la alcabala en la Aduana porteña- nos permitió extraer datos tales como: fechas de salida y llegada, peso y/o volumen de la carga al partir (y eventualmente al arribar), identidad de los transportistas, percances ocurridos en el viaje, etc.

Uno de los años escogidos para realizar el trabajo es 1820, año elegido pues fue tremendamente conflictivo en el marco de las luchas civiles, las nacientes autonomías provinciales y la inestabilidad de la frontera sur, producto del estado de agitación entre los indios pampas, en el plano interno, y con una situación externa para nada estable: inexistencia de vínculos al menos normales - con Chile, pérdida del Alto Perú (y la consiguiente amenaza sobre las provincias norteñas), aislacionismo de Paraguay e invasión lusitana en la Banda Oriental. Por supuesto que todas estas circunstancias se vieron reflejadas, en los Libros de Aduana de Buenos Aires, principal fuente en que se ha basado el análisis de dicho año. De allí que 1820 sirve como muestra para el estudio de los mecanismos del transporte en el contexto de la violencia revolucionaria desatada una década antes, en comparación con el desarrollo del mismo en épocas más pacíficas, tal cual fue el período colonial tardío. En ese sentido, tratamos de exponer los problemas específicos que alteraron el normal desenvolvimiento del transporte.

Por medio de distintas fuentes hemos realizado, además, un estudio que nos brinda un panorama general sobre el movimiento de tropas de carretas y de arrias de mulas para los decenios de 1820 a 1840, y luego, sí, un análisis mucho más profundo sobre distintas características de los transportistas, durante los años 1820, 1831-1835 y 1839-1851, gracias a los datos extraídos de la contribución directa. ${ }^{50}$ Este impuesto al comercio interior alcanzaba al 4 por mil del total de los precios de aforo de los productos y está asentado en los Manifiestos de comercio consultados, los cuales sin embargo no son tan ricos en información como las Guías correspondientes a la alcabala.

50 La Contribución Directa dejó de cobrarse entre septiembre de 1835 y abril de 1839. 
En síntesis, para tratar los problemas generales del transporte, hemos utilizado las siguientes fuentes: $22-1-2 / 4$.

—año 1820: AGN, Aduana de Buenos Aires, Entradas Terrestres, III,

—años 1822-1824: Registro Estadístico de la Provincia de Buenos Aires, año 1822: n. ${ }^{\circ} 1$, febrero 15 de 1822 , pág. $12 ;$ n. $^{\circ}$ 2, marzo 15, pág. 40; n. ${ }^{\circ}$, abril, págs. 57-58; n. ${ }^{\circ}$ 4, mayo, pág. 80; n. ${ }^{\circ}$ 5, junio, págs. 104-105; n. ${ }^{\circ}$, julio, págs. $121-122$; n. ${ }^{\circ} 7$, agosto, pág. $141 ;$ n. ${ }^{\circ} 8$, septiembre, pág. $151 ;$ n. ${ }^{\circ}$, octubre, págs. $170-171 ;$ n. $^{\circ} 10$, noviembre, págs. $185-186$; n. ${ }^{\circ} 11$, diciembre, págs. 205-206; n. ${ }^{\circ} 12$, marzo de 1823 , págs. $13-14$ y 30 (resumen anual); año 1823: n. ${ }^{\circ} 13$, trimestre $1 .^{\circ}$ de 1823 , pág. $42 ;$ n. ${ }^{\circ} 14$, trimestre $2 .^{\circ}$, págs. $69-70 ;{ }^{\circ}{ }^{\circ} 15$, semestre $2 .^{\circ}$, págs. $110-111$ y 131 (resumen anual); año 1824: n. ${ }^{\circ} 16$, semestre $1 .^{\circ}$ de 1824 , pág. 147 ; n. ${ }^{\circ} 17$, semestre $2 .^{\circ}$, págs. 156 y 171 (resumen anual). Debemos aclarar que el n. ${ }^{\circ} 16$ llega hasta la página $160 \mathrm{y} \mathrm{el} \mathrm{n.}{ }^{\circ} 17$ comienza en la 143.

—años 1828-1831: Registro Estadístico del Estado de Buenos Aires, 1858 , t. 1, Buenos Aires, Imprenta de la Tribuna, 1859, págs. 144-145 (1828); 1857, t. 2, 1858, págs. 147-148 (1829); 1856, t. 2, 1857, págs. 120121 (1830); 1857, t. 1, 1858, págs. 167-168 (1831). La información sobre 1829 y 1831 también se puede encontrar en AGN, Censos (1813-1861), Tabla general..., X, 42-8-5.

—años 1830-1850: Silvia Cristina Mallo, Amalia Latroubesse de Díaz y María Concepción Orruma, "El comercio entre Buenos Aires y las Provincias de 1830 a 1835", en Primer Congreso de Historia Argentina y Regional, Buenos Aires, 1973, págs. 263-276; Hebe Judith Blasi, "Las relaciones comerciales entre las provincias y Buenos Aires (1835-1839)", en Primer Congreso..., págs. 277-285; y María Clelia Cano, María Elena Infesta, Susana Palmira Martínez, Susana Clementina Urchoeguía y Marta Edit Valencia, "Comercio interprovincial, 1840-1850", en Primer Congreso..., págs. 287-304. La cuestión de las limitaciones de la Gaceta Mercantil como fuente puede verse en la página 269.

El tema de "los hombres del transporte" fue analizado a través de las siguientes fuentes:

—año 1820: AGN, Aduana de Buenos Aires, Entradas Terrestres, III, $22-1-2 / 4$. 
—años 1831-1835: AGN, Contribución Directa, III, 1831: $23-1-9 / 10$.

1832: $23-2-10 / 13$.

1833: $23-3-13$ a $23-4-3$.

1834: $23-5-4 / 6$.

1835: 23-7-4/6.

—años 1839-1851: AGN, Receptoría. Cargo y Data, III, 1839: $24-5-1 / 4$.

1840: $24-5-5 / 6$ a $24-6-1$.

1841: $24-6-2$ a $24-7-3$.

1842: $24-7-4$ a $24-8-5$.

1843: 24-9-1 a 24-10-5.

1844: $24-10-6$ a $25-1-5$.

1845: $25-1-6$ a $25-3-2$.

1846: $25-3-3 / 7$.

1847: $25-4-1$ a $25-5-3$.

1848: $25-5-4$ a $25-6-6$.

1849: $25-6-7$ a $25-9-2$.

1850: $25-9-3$ a $25-11-7$.

1851: 26-1-1/5.

Este estudio lo hemos realizado por medio del análisis de 312 guías de comercio correspondientes a 1820 (195 de la carrera de Cuyo y 117 de la del Norte) y 4.769 operaciones comerciales entre 1831 y 1851 (1.929 relativas a la ruta cuyana y 2.840 a la norteña), a las que se deben agregar 124 más atinentes a los viajes desde Santa Fe entre 1839 y 1847. 



\section{Anexo estadístico}

CUADRo 1A

TRANSPORTE DE MERCANCÍAS POR MEDIO DE TROPAS DE CARRETAS Y ARRIAS DE MULAS A TRAVÉS DEL ESPACIO RIOPLATENSE, 1822-1824

Entradas a Buenos Aires

\begin{tabular}{rrrrrrr} 
& Tropas & Carretas & Arrias & Carga & Peones & Bestias \\
\hline 1822 & 111 & 1.259 & 190 & 295.768 & 3811 & 30.365 \\
1823 & 84 & 1.206 & 182 & 276.894 & 3226 & 26.029 \\
1824 & 72 & - & 82 & 217.928 & - & -
\end{tabular}

Salidas de Buenos Aires

\begin{tabular}{rrrrrrr} 
& Tropas & Carretas & Arrias & Carga & Peones & Bestias \\
\hline 1822 & 84 & 1042 & 82 & 138.736 & 2.205 & 18.797 \\
1823 & 55 & 729 & - & 104.368 & 987 & 6.993 \\
1824 & 33 & - & 1 & 66.696 & - & -
\end{tabular}


MIGUEL ÁNGEL ROSAL

CUADRO 1B

PROCEDENCIA Y DESTINO DE LAS TROPAS DE CARRETAS

Y ARRIAS DE MULAS, 1822-1824

Procedencia

\begin{tabular}{lrrrrrr} 
& \multicolumn{3}{c}{ Tropas } & \multicolumn{3}{c}{ Arrias } \\
Origen & 1822 & 1823 & 1824 & 1822 & 1823 & 1824 \\
\hline Mendoza & 22 & 28 & 21 & 82 & 91 & 50 \\
San Juan & 1 & - & 3 & 43 & 89 & 32 \\
San Luis & - & - & - & 3 & 2 & - \\
Córdoba & 54 & 41 & 38 & - & - & - \\
Sgo. Estero & 6 & 1 & 1 & - & - & - \\
Tucumán & 12 & 14 & 9 & - & - & - \\
No indica & 16 & - & - & 64 & - & - \\
Total & 111 & 84 & 72 & 192 & 182 & 82
\end{tabular}

Destino

Tropas Arrias

\begin{tabular}{lrrrrrr} 
Destino & 1822 & 1823 & 1824 & 1822 & 1823 & 1824 \\
\hline Mendoza & 21 & 16 & 8 & 30 & 1 & - \\
San Juan & - & 2 & - & 19 & 1 & 1 \\
San Luis & - & - & - & 1 & - & - \\
Córdoba & 33 & 29 & 21 & - & - & - \\
Sgo. Estero & 1 & 1 & - & - & - & - \\
Tucumán & 7 & 7 & 2 & - & - & - \\
Salta & 2 & - & 1 & - & - & - \\
No indica & 20 & - & - & 51 & - & - \\
\hline Total & 84 & 55 & 32 & 101 & 2 & 1
\end{tabular}

Fuente: REPBA, 1822-1824. 
EL TRANSPORTE TERRESTRE A TRAVÉS DEL ESPACIO RIOPLATENSE

\section{CuAdro 2}

TRANSPORTE DE MERCANCÍAS POR MEDIO DE TROPAS DE CARRETAS Y ARRIAS DE MULAS A TRAVÉS DEL ESPACIO RIOPLATENSE, 1828-1831

Entradas a Buenos Aires

\begin{tabular}{lccccr} 
& Tropas & Personas & Bueyes & Carretas & Arrobas \\
\hline 1828 & 56 & 1.134 & 6.685 & 773 & 111.627 \\
1829 & 43 & 932 & 5.164 & 663 & 92.555 \\
1830 & 45 & 901 & 5.006 & 631 & - \\
1831 & 13 & 312 & 1.451 & 197 & -
\end{tabular}

Entradas a Buenos Aires

\begin{tabular}{lccccr} 
& Arrias & Personas & Mulas & Cargas & Arrobas \\
\hline 1828 & 90 & 811 & 8.613 & 5.744 & 69.000 \\
1829 & 10 & 91 & 882 & 597 & 6.874 \\
1830 & 5 & 32 & 320 & 176 & - \\
1831 & 9 & 63 & 401 & 263 & -
\end{tabular}

Salidas de Buenos Aires

\begin{tabular}{lccccr} 
& Tropas & Personas & Bueyes & Carretas & Arrobas \\
\hline 1828 & 22 & 474 & 2.475 & 306 & 43.688 \\
1829 & 33 & 784 & 3.766 & 490 & 70.416 \\
1830 & 41 & 761 & 4.373 & 584 & - \\
1831 & 11 & 258 & 1.126 & 164 & -
\end{tabular}

Salidas de Buenos Aires

\begin{tabular}{cccccc} 
& Arrias & Personas & Mulas & Cargas & Arrobas \\
\hline 1828 & - & - & - & - & - \\
1829 & - & - & - & - & - \\
1830 & 3 & 54 & 214 & 30 & - \\
1831 & - & - & - & - & -
\end{tabular}

Fuente: REEBA, 1856-1858. 
MIGUEL ÁNGEL ROSAL

\section{CUADRo 3}

MOVIMIENTO GENERAL DE TROPAS DE CARRETAS Y ARRIAS DE MULAS

HACIA Y DESDE BUENOS AIRES, 1830-1845

Entradas

Salidas

\begin{tabular}{lrrrr} 
& Tropas & Arrias & Tropas & Arrias \\
\hline 1830 & 47 & 14 & 20 & - \\
1831 & 25 & 8 & 12 & - \\
1832 & 104 & 51 & 45 & - \\
1833 & 55 & 56 & 27 & - \\
1834 & 75 & 30 & 25 & - \\
1835 & 68 & 16 & 21 & - \\
1836 & 48 & 9 & 30 & - \\
1837 & 51 & 17 & 22 & - \\
1838 & 42 & 38 & 15 & - \\
1839 & 49 & - & 17 & - \\
1840 & 14 & 4 & 5 & - \\
1841 & 7 & 3 & - & - \\
1842 & 14 & 6 & - & - \\
1843 & 31 & 18 & 14 & 4 \\
1844 & 8 & 6 & 3 & - \\
1845 & 15 & 1 & 3 & -
\end{tabular}

Fuente: La Gaceta Mercantil (Ver fuentes). 
CUADRO 4

CONFORMACIÓN DE TROPAS DE CARRETAS Y ARRIAS DE MULAS, 1822-1831

Tropas

\begin{tabular}{llcccr} 
Fecha & Orig./Dest. & Carretas & Carga (@) & Peones & Bueyes \\
\hline Mar 1822 & De Córdoba & 13 & 1.950 & 19 & 180 \\
Mar 1822 & N.I. Destino & 12 & 0 & 18 & 141 \\
May 1828 & A Córdoba & 6 & 858 & 13 & 60 \\
Jun 1828 & A Córdoba & 14 & 1.796 & 20 & 120 \\
Sep 1828 & A Córdoba & 4 & 572 & 7 & 60 \\
Oct 1828 & De Mendoza & 18 & 2.574 & 25 & 190 \\
Ene 1830 & De Río Cuarto & 15 & 2.145 & 22 & 45 \\
Jul 1831 & A Córdoba & 19 & - & 30 & 80 \\
Nov 1831 & A Córdoba & 14 & - & 24 & 180
\end{tabular}

Arrias

\begin{tabular}{llrrr} 
Fecha & Orig./Dest. & Carga (@) & Peones & Mulas \\
\hline Mar 1822 & A Cuyo & 96 & 8 & 80 \\
Nov 1822 & A San Juan & $144^{*}$ & 10 & 84 \\
Jun 1823 & A Mendoza & 144 & 8 & 130 \\
Nov 1823 & A San Juan & 96 & 5 & 30 \\
Mar 1824 & A San Juan & 50 & 7 & 66 \\
Oct 1829 & De Mendoza & 480** & 12 & 70 \\
Ago 1830 & De San Juan & 52 Cargas & 12 & 100 \\
Oct 1830 & De Tucuman & 25 Cargas & 6 & 40 \\
Ago 1831 & De San Juan & 26 Cargas & 5 & 40 \\
Sep 1831 & De San Juan & 48 Cargas & 10 & 80 \\
\hline * Son 12 Cargas & & & \\
F* Son 40 Cargas & & &
\end{tabular}

